\title{
An application of artificial neural network to predict the added value of oil, gas and petroleum industry products
}

\author{
Hossein Vazifehdust $^{\mathrm{a}}$, Hamidreza Vaezi Ashtiani ${ }^{\mathrm{b}^{*}}$ and Naeemeh Safavi Mobarhan $^{\mathrm{b}}$
}

${ }^{a}$ Assistant Professor, Department of Business Management, Science and Research Branch, Islamic Azad University, Tehran, Iran ${ }^{b}$ Department of Business Management, Science and Research Branch, Islamic Azad University, Tehran, Iran

\section{CHRON I C L E}

\section{Article history:}

Received May 12, 2013

Received in revised format

25 June 2013

Accepted 27 June 2013

Available online

July 42013

Keywords:

Oil and Gas industry

Neural network

Forecasting added value

\section{Introduction}

During the past few years, many analysts and government agencies try to anticipate economic variables to adjust their policies. The duty of anticipation experts is to find the best possible method of anticipation with minimum error. One of the most effective methods is called artificial neural networks, which is a simplified model based on central neural system, which transfers the hidden rule from data to the network structure. Energy sector plays a key role in oil and its products exporting countries' development and it is one of the development pillars in many developing countries. There is no full compatibility between anticipation and reality and there is no unique as the best method to use for future prediction. The duty of anticipation experts is to find the best possible method of

*Corresponding author. Tel: +98219122261081

E-mail address: hr_vaeziashtiani@yahoo.com(M. Moshkelati)

(c) 2013 Growing Science Ltd. All rights reserved.

doi: $10.5267 / j . m s 1.2013 .07 .004$ 
anticipation with minimum error. The governments should be able to anticipate economic variables to adjust their policies.

Growth domestic product (GDP) is one of the most important national calculations as a picture of economic performance, decision indexes, economic policies, macroeconomics analysis and international comparison index. One of the calculation methods is sum of added value in subsidiaries and country's economic sections. Considering the importance of energy section in Iran's economic development, anticipation of added value in energy subsidiaries seems to be important. Considering the importance of anticipation, proper selection of tools to achieve goals of study and also anticipation steps have special importance.

1. Surveying fluctuation and trend of added value changes in Iran's Energy Subsidiaries (Added value in oil group with current value, added value of crude oil exporting with current value, added value of gas production with current value, added value of petroleum with current value).

2. Anticipation of added value in oil industries, crude oil exporting, production of gas and petroleum (with current value).

With regard to importance of energy section in oil exporting countries such as Iran, anticipation of added value in energy section have always been considered by planners and economists to plan for exchange incomes and satisfying country's needs. Thus, importance of anticipation of added value in energy section and achieving the planned goals are the main challenge for the economic authorities and planners. With a view to the anticipation importance, proper selection of anticipation tools to reach the goals of study and plays essential role for economic development. Usage of artificial neural networks due to its comprehensive application and its accuracy is one of the most efficient tools during the recent years especially in field of finance and micro economics.

The unprecedented success of neural networks as a powerful tool to analyze data in theoretical sciences has created substantial motivation among economists to pay special attention to hits modeling method. First, considering that these models needed large amount of data, surveying and modeling in economics have been started using neural networks in financial markets. Vov and Lou (1993) anticipated United States stock price index using daily data over the period 1971-1990. Neural networks in field of financial economics have become popular and micro-economic and econometrics experts have been interested in using neural networks to anticipate macro-economic events (Juan \& White, 1994).

Salam et al. (2012) performed A comparative analysis between the parametric based model and those upon neural networks model were considered in order to determine the most accurate method to predict the cost of a main landing gear. Lahmiri (2012) implemented various technical analysis measures and resilient back-propagation neural networks to predict the price level of five major developed international stock markets, namely the US S \& P500, Japanese Nikkei, UK FTSE100, German DAX, and the French CAC40. They compared four categories of technical analysis measures including indicators, oscillators, stochastics, and indexes. The out-of-sample simulation results showed a strong evidence of the effectiveness of the indicators category over the oscillators, stochastics, and indexes. In addition, he found that combining all these measures lead to an increase of the prediction error.

According to Chen et al. (2004), predicting currency movements has always been a problematic task as most conventional econometric models are not able to forecast exchange rates with significantly higher accuracy than a naive random walk model. For large multinational firms, which conduct substantial currency transfers in the course of business, being able to predict the movements of 
exchange rates can result in considerable improvement in the overall profitability of the firm. Chen et al. $(2003$, 2004) applied the General regression neural network (GRNN) to predict the monthly exchange rates of three currencies, British pound, Canadian dollar, and Japanese yen. Their empirical experiment stated that the performance of GRNN was better than other neural network and econometric techniques included in this study. The results demonstrated the predictive strength of GRNN and its potential for solving financial forecasting problems.

Chen et al. (2003) investigated an application of neural networks in Taiwan as an emerging financial market for forecasting and Trading the Taiwan Stock Index. They attempted to model and to predict the direction of return on the Taiwan Stock Exchange Index, one of the fastest growing financial exchanges in developing Asian countries. Their approach was based on the notion that trading strategies guided by forecasts of the direction of price movement could be more effective and lead to higher profits. The Probabilistic Neural Network (PNN) was used to forecast the direction of index return after it was trained by historical data. The forecasts were applied to various index trading strategies, where the performances were compared with those generated by the buy and hold strategy, and the investment strategies guided by the forecasts estimated by the random walk model and the parametric Generalized Methods of Moments (GMM) with Kalman filter. Empirical results stated that the PNN-based investment strategies could obtain higher returns than other investment strategies examined in their study. The influences of the length of investment horizon and the commission rate are also considered.

Chen et al. (2004) in another study assessed the regression Neural Network for error correction in foreign exchange forecasting and trading. They proposed an adaptive forecasting approach, which combined the strengths of neural networks and multivariate econometric models. This hybrid approach contained two forecasting stages. In the first stage, a time series model generated estimates of the exchange rates. In the second stage, General Regression Neural Network was implemented to correct the errors of the estimates. A number of tests and statistical measures were then implemented to compare the performances of the two-stage models (with error-correction by neural network) with those of the single-stage models (without error-correction by neural network). Both empirical and trading simulation experiments suggested that the proposed hybrid approach not only produced better exchange rate forecasts but also resulted in higher investment returns than the single-stage models.

Toth et al. (2000) performed an empirical investigation to find out about short-term rainfall prediction models for real-time flood forecasting. The study compared the accuracy of the short-term rainfall forecasts obtained with time-series analysis techniques, using past rainfall depths as the only input information. The techniques proposed here were linear stochastic auto-regressive moving average (ARMA) models, artificial neural networks (ANN) and the non-parametric nearest-neighbors method. The rainfall forecasts calculated using the considered methods were then routed through a lumped, conceptual, rainfall-runoff model, thus implementing a coupled rainfall-runoff forecasting procedure for a case study on the Apennines mountains, Italy. The study analyzed and compared the relative benefits and limitations of each time-series analysis technique, implemented for issuing rainfall forecasts for lead-times varying from 1 to $6 \mathrm{~h}$. The results also showed how the considered time-series analysis techniques, and especially those based on the use of ANN, could provide a significant improvement in the flood predicting accuracy compared with simple rainfall prediction approaches of heuristic type, which were often applied in hydrological practice.

Hsiao and Whang (2009) performed an investigation on insolvency prediction and efficient classification approach for life insurers in Taiwan. Insurer supervision is often interested in monitoring the financial solvency of insurance companies and protecting the rights of consumers, improving the related legislation and regulatory policy. After the Asian crisis in July of 1997, the economic environment grew worse. 
Hsiao and Whang (2009) evaluated the financial soundness by implementing the rating systems of the CAMEL-S and the RBC model. Further, they tried to realize whether there are significant differences of financial stability between domestic and foreign life insurers from 1998 to 2002 using ANN. They reported that the ANN could yield better results for classification than the traditional discriminant method, since ANN contained an accurate discrimination rate of $95.2 \%$ with a lower Type I error of 0.0274 , and Type II error of 0.0769 . The results of the mentioned studies support the hypothesis that anticipation by using the regression methods has less error in comparison with nonregression methods. In addition, we may get better results using ANN models, which would help us anticipate added value in subsidiaries of Iran' energy in different periods.

\section{The proposed model}

During the past few years, many people have become interested in using ANN models for data predictions. They are simplified model of central neural system and transfer the hidden rule above data into the network structure by processing on experimental data such as brain. A neural network consists of artificial neurons. Neuron or node is the smallest data processing unit, which makes the basis for neural networks performance (Menhaj, 1998). Each of neurons receives the inputs and creates an output signal after processing on them. Therefore, each neuron plays as center of processing and data information distribution in the network and has its exclusive input and output. Fig. 1 is schematic of single input neuron and the figures of $p$ and $a$ are input and output, respectively.

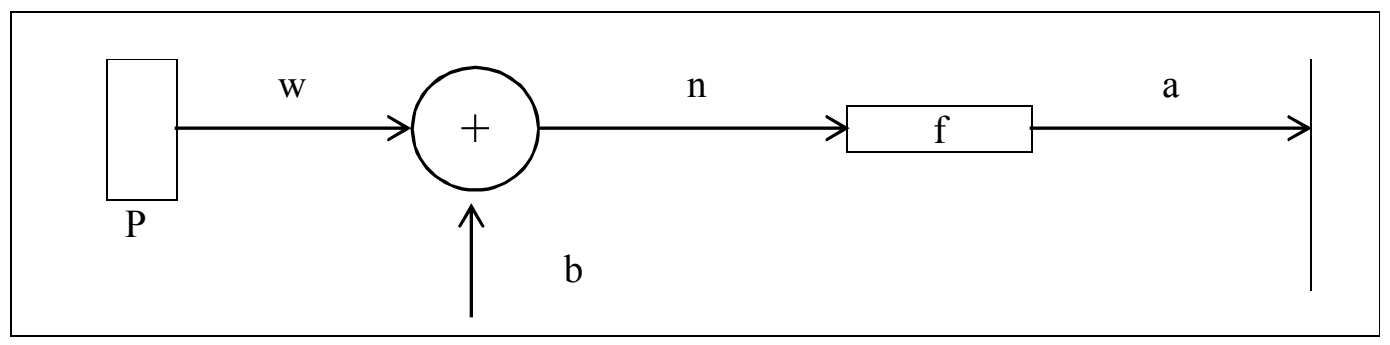

Fig. 1. Single input neuron model

In the current study, first, the fluctuation and previous trend of added value in energy subsidiaries are analyzed and then, some of central indexes and transmittals including maximum, minimum, mean and variance are analyzed and compared separately. This helps us survey more on added value fluctuation in energy section added value on oil production, gas production, oil exporting and petroleum exporting with current value. In order to survey data static features, two tests of unit root Deiki-Fouller and generalized Deiki-Fouller are implemented as step by step tests then, the best network is chosen to anticipate added value in subsidiaries of energy section which was feed forward network. The reason of selecting this network is because of the existence of behavior and data. For the training and testing the network, the data are divided in two groups and the method performs the same as anticipation quantitative methods.

To define input layer neurons number which are equal to auto regressive vector rank in ARMA method, the rank of auto regressive (p) and mobile mean (q) are implemented based on proposed method of Son et al. (2004). Finally, the validity of model has been checked by comparing between anticipated added value by the model and measured values based on some of the statistical years, which has not been used in network training. For this aim, the statistical methods of Root Mean Square Method (RMSE), Index of Agreement (d) (Willmott, 1982) and Minimum Absolute Error (MAE) have been used. RMSE, $\mathrm{d}$ and MAE are calculated as follows, 


$$
\begin{aligned}
& R M S E=\left[\frac{\sum_{i=1}^{n}\left(p_{i}-o_{i}\right)^{2}}{n}\right]^{1 / 2} \times \frac{100}{\bar{o}}, \\
& d=1-\frac{\sum_{i=1}^{n}\left(p_{i}-o_{i}\right)^{2}}{\sum_{i=1}^{n}\left(\left|p_{i}^{\prime}\right|+\left|o_{i}^{\prime}\right|\right)^{2}}, p_{i}^{\prime}=p_{i}-\bar{p}, o_{i}^{\prime}=o_{i}-\bar{o}, \\
& M A E=\frac{\sum_{i=1}^{n}\left|p_{i}-o_{i}\right|}{n},
\end{aligned}
$$

where $p_{i}$ and $o_{i}$ are predicted and simulated values, respectively. In addition, $\bar{p}$ and $\bar{o}$ are average values of $p_{i}$ and $o_{i}$, respectively. The lower limit of RMSE is 0 and value of RMSE shows how much the forecasted value is different from the observed value. In addition, $d$ shows the model performance and it is between 0 and 1, the closer to 1, the better it is. MAE shows the mean of error and the lower amount shows more accuracy. For performing different steps, Eviews, Microfit, SPSS, MATLAB and -Neural Network software have been used (Alborzi, 2001; Cao \& Tay, 2001).

\section{The results}

In this section, first, the fluctuation of added value in energy section subsidiaries including oil group added value with current value, crude oil exporting added value with current value, gas production added value with current value, petroleum added value with current value have been surveyed over the period 1959-2004.

Finally, after proper testing, the added value related to energy subsidiaries has been anticipated based on the best anticipation method. In order to survey fluctuation of added value related to energy subsidiaries, some central and transmittal indexes including maximum, minimum, mean and variance have been analyzed and compared, separately. Table 1 demonstrates the summary of our findings using SPSS software.

\section{Table 1}

Central and transmittal indexes related to added value in energy subsidiaries

\begin{tabular}{ccccc}
\hline Variable name & Oil section & Oil exporting section & Gas section & Petroleum section \\
\hline Maximum & 350461 & 160383.3 & 5825.2 & 43876.3 \\
Minimum & 34 & 29.5 & 0.25 & 4.2 \\
Mean & 28404.021 & 13395.993 & 298.882 & 2304.645 \\
Variance & 4876154515 & 920435974.8 & 881066.818 & 50238556.7 \\
\hline The figures presented in Billion IRR & & &
\end{tabular}

\subsection{Static test}

In order to survey static features of the data, two tests of unit root Dickey-Fuller and generalized Dickey-Fuller have been used as step by step methods (Dickey \& Fuller, 1979). The static test for 4 variables of added value in energy subsidiaries including oil group with current value, crude oil exporting added value current value, gas production added value with current value, petroleum added value with current value have been performed by Eviews and the results are presented in Table 2 as follows, 
Table 2

The summary of Dickey-Fuller test

\begin{tabular}{lccc}
\hline Variable name & $\mathrm{t}$ variable amount & Number of optimized stop & Static degree \\
\hline $\begin{array}{l}\text { Added value in oil group } \\
\begin{array}{l}\text { Added value in crude oil } \\
\text { exporting with current value }\end{array}\end{array}$ - $^{* .968^{* * *}}$ & 1 & $\mathrm{I}(0)$ \\
$\begin{array}{l}\text { Added value of gas production } \\
\text { with current value }\end{array}$ & $-3.720^{* * *}$ & 0 & $\mathrm{I}(0)$ \\
$\begin{array}{l}\text { Added value of petroleum with } \\
\text { current value }\end{array}$ & $-4.505^{* * *}$ & 0 & $\mathrm{I}(0)$ \\
\hline$*^{* * *}$ and ${ }^{* * *}$ are significance level in $10 \%, 5 \%$ and $1 \%$ respectively. & 0 & $\mathrm{I}(0)$ \\
\hline
\end{tabular}

Based on the results, except added value variable in oil and crude oil exporting sections, all of the variables are in static level. However, the both variables have been static after one time deduction and therefore, they are first order static variables.

\subsection{ANN method}

First about the designed neural network, it should be mentioned that the best tested network type is feed forward network. The reason is associated with the data behavior and type. In this research, a feed forward (FF) network is composed of 46 inputs as 46 years and to determine number of input and hidden layer neurons, the trial and error method has been used. The number of input layer neurons which is equal of auto regressive vector rank in ARMA method, was 1 to 5 and the number of hidden layer neurons at this variable network (depends on data type, between 1 to 20 hidden layers) has been designed as 5 output layers. This data network has been called as a time series and they would be put in its input sequences.

In the current study, to determine input layer neurons number which are equal to auto regressive vector rank in ARMA method, the auto regressive rank (p) and mobile mean (q) have been used. First, the models with different ranks of $p$ and $q$ have been estimated and then, the best rank of $q$ and $p$ based on the least value of these criteria have been selected using extracted Schwarz Bayesian Acaiq criterion statistics.

\subsection{Training and testing}

To design and train the ANN, data have been divided in two series of training data and testing data. For this aim, considering the low amount of data and based on previous studies results and also similar to common anticipation methods, around $90 \%$ of the data have been used as training data and the remaining $10 \%$ have been used as testing data. These data passes between 20 to 10000 epochs to reach to the least value of RMS based on their behavior as regular or irregular. In this step, the training step is finished and $10 \%$ of the remaining data have been used in testing section. Then, the results regarding anticipating added value in energy subsidiaries would be presented using all the existing data. The training algorithm used in this study was Levenberg-Marquardt Algorithm.

\subsection{The results of forecasted results}

In feed forward network, considering the optimized stop has been obtained from ARMA and ARIMA methods according to Schwarz Bayesian criterion Statistics achieved in previous sections, the number of data related to first stop of each variable has been feed to the network. Then, after recognizing data pattern, the next data, which is the first data related to the next years, would be anticipated. Eventually, this data would be compared to the real data and this step would be continued until the least difference with the real data would be achieved. This act would be repeated until all of the data finish. Table 3 demonstrates the results of our training part where $d$ presents model performance and its value would be between 0 and 1, a closer value to 1 means better result and shows proper fitting of 
the proposed ANN model and also higher amount of compatibility between observed added value in energy subsidiaries and simulated added value for energy subsidiaries.

Table 3

The summary of trained section of ANN

\begin{tabular}{|c|c|c|c|c|c|c|c|c|c|c|c|c|}
\hline \multirow[b]{2}{*}{ Cycle/Section } & \multicolumn{12}{|c|}{ Cycle } \\
\hline & 1 & 2 & 3 & 4 & 5 & 6 & 7 & 8 & 9 & 10 & 11 & 12 \\
\hline Petroleum & 0.99 & 0.99 & 0.99 & 0.98 & 1.00 & 1.00 & 0.98 & 0.89 & 1.00 & 1.00 & 0.95 & 0.99 \\
\hline Oil exporting & 1.00 & 0.99 & 0.93 & 0.70 & 1.00 & 0.99 & 0.98 & 0.99 & 1.00 & 1.00 & 0.76 & 0.98 \\
\hline Gas production & 1.00 & 1.00 & 1.00 & 0.98 & 1.00 & 0.98 & 0.96 & 0.92 & 1.00 & 1.00 & 0.88 & 0.98 \\
\hline Oil group & 0.93 & 0.98 & 0.99 & 0.82 & 1.00 & 0.95 & 0.99 & 0.92 & 0.94 & 0.96 & 0.70 & 0.73 \\
\hline
\end{tabular}

In addition, Table 4 shows a summary of results obtained from anticipation of added value in energy sections over the period 2005-2009,

Table 4

The summary of forecasted results

\begin{tabular}{lccccc}
\hline Subsidiaries/anticipation years & 2005 & 2006 & 2007 & 2008 & 2009 \\
\hline Petroleum & 60542.1 & 101945.68 & 145620.97 & 202377.97 & 295400 \\
Oil exporting & 286709.88 & 401335.28 & 558222.14 & 782499.88 & 1092006 \\
Gas production & 11248.23 & 17473.22 & 27087.06 & 42272.08 & 65370.04 \\
Oil group & 352992.34 & 497695.48 & 679856.16 & 951482.26 & 1316000 \\
\hline
\end{tabular}

\section{Discussion and conclusion}

As far as energy section has the key role in economic development of all oil and petroleum exporting countries and it is always mentioned as one of the most important development principles, paying attention by politicians, economics and investment experts can help country's economic growth. The sum of subsidiaries and country's economic sections added values is one of the most important national accounts indexes as an economic performance image, economic decisions and policies index, macro-economic analysis index and international comparison index.

In this paper, we have presented an empirical investigation to use ANN for estimating added value of oil products. The results of our study have shown that the proposed study of this paper has been able to provide good estimation for oil-based products. The results of our study are somewhat consistent with other survey results accomplished in Iran. Khaloozadeh and Khaki Sedigh (2003), for instance, surveyed different models and ANN abilities in long-term anticipation of Tehran's stock exchange price, their results have been compared with the other models in order to anticipate stock price for next 30 days. The results showed the linear classic models were not efficient to anticipate the future due to dynamicity of stock price in Tehran stock exchange and neural network model has more ability for long-term changes anticipation.

Considering increasing importance of energy section in Iran's economic development and results obtained from anticipation of added value in energy subsidiaries have shown uptrend in fourth development plan especially in two sections of oil exporting and oil group sections. Therefore, it is recommended to the politicians and government's economic experts to help these two sections by absorbing internal and foreign investments.

\section{Acknowledgment}

The authors would like to thank the anonymous referees for constructive comments on earlier version of this paper. 


\section{References}

Alborzi, M. (2001). Introduction to Neural Networks. $1^{\text {st }}$ ed., Sharif University of Technology publication institute, 137 pages.

Cao, L., \& Tay, F. E. (2001). Financial forecasting using support vector machines. Neural Computing \& Applications, 10(2), 184-192.

Chakraborty, K., Mehrotra, K., Mohan, C. K., \& Ranka, S. (1992). Forecasting the behavior of multivariate time series using neural networks. Neural networks,5(6), 961-970.

Chase, R. B., Jacobs, F. R., Aquilano, N. J., \& Ren, J. (2006). Operations management for competitive advantage. $9^{\text {th }}$ ed., McGraw-Hill Irwin.

Chen, A. S., Leung, M. T., \& Daouk, H. (2003). Application of neural networks to an emerging financial market: forecasting and trading the Taiwan stock index. Computers \& Operations Research, 30(6), 901-923.

Chen, A. S., \& Leung, M. T. (2004). Regression neural network for error correction in foreign exchange forecasting and trading. Computers \& Operations Research, 31(7), 1049-1068.

Darbellay, G. A., \& Slama, M. (2000). Forecasting the short-term demand for electricity: Do neural networks stand a better chance?. International Journal of Forecasting, 16(1), 71-83.

Dickey, D. A., \& Fuller, W. A. (1979). Distribution of the estimators for autoregressive time series with a unit root. Journal of the American statistical association, 74(366a), 427-431.

Hsiao, S. H., \& Whang, T. J. (2009). A study of financial insolvency prediction model for life insurers. Expert systems with applications, 36(3), 6100-6107.

Jay, H., \& Barry, R. (2001). Principles of Operations Management, $4^{\text {th }}$ ed., Prentice Hall Inc., New Jersey.

Khaloozadeh, H., \& Khaki Sedigh, A. (2003). Evaluating methods of the share price forecastability in Tehran stock exchange. Journal of Modarres, The Faculty of humanities Tarbiat Modarres University, Quarterly Journal, 7(3), 61-89. (In Persian).

Lahmiri, S. (2012). Resilient back-propagation algorithm, technical analysis and the predictability of time series in the financial industry. Decision Science Letters, 1(2), 47-52.

Leung, M. T., Chen, A. S., \& Daouk, H. (2000). Forecasting exchange rates using general regression neural networks. Computers \& Operations Research,27(11), 1093-1110.

Menhaj, M. B. (1998). Fundamentals of neural networks. Computational intelligence, 1, 222-229.

Oskouei, M. (2002). Application of Neural Networks in time series anticipation. Iranian Journal of Economic Research, 12.

Olson, D., \& Mossman, C. (2003). Neural network forecasts of Canadian stock returns using accounting ratios. International Journal of Forecasting, 19(3), 453-465.

Pesaran, M. H., \& Pesaran, B. (1997). Working with Microfit 4.0: interactive econometric analysis. Oxford University Press.

Salam, A., Defersha, F \& Bhuiyan, N. (2012). A case study to estimate costs using Neural Networks and regression based models. Decision Science Letters, 1(1), 1-10.

Son, J. S., Lee, D. M., Kim, I. S., \& Choi, S. K. (2004). A study on genetic algorithm to select architecture of a optimal neural network in the hot rolling process. Journal of Materials Processing Technology, 153, 643-648.

Tkacz, G. (2001). Neural network forecasting of Canadian GDP growth. International Journal of Forecasting, 17(1), 57-69.

Toth, E., Brath, A., \& Montanari, A. (2000). Comparison of short-term rainfall prediction models for real-time flood forecasting. Journal of Hydrology, 239(1), 132-147.

Willmott, C. J. (1982). Some comments on the evaluation of model performance. Bulletin of the American Meteorological Society, 63(11), 1309-1313. 